\title{
ENSINO DE HISTÓRIA E A TEMÁTICA DA ALIMENTAÇÃo: Possibilidades acerca da identidade, memória e pertencimento Icoaraci/PA.
}

\author{
TEACHING OF HISTORY AND THE THEME OF FOOD: \\ Possibilities about identity, memory and belonging. \\ Icoaraci / PA
}
ENSEÑANZA DE LA HISTORIA Y EL TEMA DE LA AKIMANTACIÓN: Posibilidades sobre identidad, memoria y pertenencia. Icoaraci / PA

\section{Resumo}

Williomar de Souza Peixoto ${ }^{1}$

A alimentação como elemento cultural ajuda a demarcar traços múltiplos de diferentes identidades nas sociedades no decorrer do tempo e em diversos contextos históricos. Por meio do hábito de alimentar-se, que é uma das necessidades humana, podemos lançar mãos de análises históricas conforme este hábito se transforma em rituais de prazer e convenções sociais, que caracterizam peculiaridades culturais, divide classes, ao mesmo tempo que possibilita diferentes formas de abordagens sobre aspectos da cultura histórica. A história da alimentação hoje possui sua importância comprovada na escrita da história. Dessa forma, o campo de pesquisa sobre o ensino de História vem ganhando novas contribuições a partir da história da alimentação. Este tema permite ao ensino de História tratar da evolução de hábitos, costumes alimentares, além de temáticas caras ao conhecimento histórico, como; trabalho, meio ambiente, problemas sociais e econômicos, ou aspectos políticos. Este artigo busca apresentar algumas perspectivas e possibilidades sobre Alimentação e Ensino de História experimentadas durante a pesquisa no âmbito do projeto de mestrado do ProfHistória/UFPA. A pesquisa baseou-se no campo do ensino patrimonial de Icoaraci (distrito de Belém) com uma turma do ensino fundamental local, propondo uma sequência didática que analise o patrimônio histórico cultural de Icoaraci, por meio de aulas oficinas, trato com fontes iconográficas antigas, entrevistas com os mais velhos, e visitação dos lugares de memória. Durante esta pesquisa os alunos e as pessoas entrevistadas apontaram variadas práticas e costumes ligados à alimentação como traços identitários, o que nos levou a tratar acerca deste tema.

Palavras chaves: Ensino patrimonial, Alimentação, Icoaraci, História da Alimentação, Ensino de História.

\footnotetext{
${ }^{1}$ Professor de História na rede básica de ensino e mestrando no Programa de Pós-Graduação em Ensino de História (ProfHistória) pela Universidade Federal do Pará (UFPA). E-mail: william.speixoto@ hotmail.com
} 


\title{
Ensino de História e a temática da alimentaçõa: \\ Possibilidade acerca da identidade, memória e pertencimento. Icoaraci/PA
}

Williomar de Souza PEIXOTO

\begin{abstract}
Food as a cultural element helps to demarcate multiple traits of different identities in societies over time and in different historical contexts. Through the habit of eating, which is one of the human needs, we can use historical analysis as this habit turns into pleasure rituals and social conventions, which characterize cultural peculiarities, divide classes, at the same time that it allows different forms approaches on aspects of historical culture. The history of food today has its proven importance in the writing of history. Thus, the field of research on the teaching of History has been gaining new contributions from the history of food. This theme allows the teaching of History to deal with the evolution of habits, eating habits, in addition to themes dear to historical knowledge, such as; work, environment, social and economic problems, or political aspects. This article seeks to present some perspectives and possibilities on Food and History Teaching experienced during research within the scope of the Master's project of ProfHistória / UFPA. The research was based on the field of heritage teaching in Icoaraci (district of Belém) with a local elementary school class, proposing a didactic sequence that analyzes the historical cultural heritage of Icoaraci, through workshops, dealing with old iconographic sources, interviews with elders, and visiting places of memory. During this research, students and people interviewed pointed out various practices and customs related to food as identity traits, which led us to address this issue.
\end{abstract}

Keywords: Heritage teaching, Food, Icoaraci, History of Food, History teaching.

\section{Resumen}

La comida como elemento cultural ayuda a demarcar múltiples rasgos de diferentes identidades en las sociedades a lo largo del tiempo y en diferentes contextos históricos. A través del hábito de comer, que es una de las necesidades humanas, podemos utilizar el análisis histórico, ya que este hábito se convierte en rituales de placer y convenciones sociales, que caracterizan las peculiaridades culturales, dividen las clases, al mismo tiempo que permiten diferentes formas. enfoques sobre aspectos de la cultura histórica. La historia de la comida hoy tiene su importancia comprobada en la escritura de la historia. Por lo tanto, el campo de investigación sobre la enseñanza de la historia ha ido ganando nuevas contribuciones de la historia de la comida. Este tema permite que la enseñanza de la Historia se ocupe de la evolución de los hábitos, los hábitos alimenticios, además de los temas que el conocimiento histórico aprecia, como; trabajo, medio ambiente, problemas sociales y económicos, o aspectos políticos. Este artículo busca presentar algunas perspectivas y posibilidades sobre la enseñanza de alimentos e historia experimentadas durante la investigación dentro del alcance del proyecto de maestría de ProfHistória / UFPA. La investigación se basó en el campo de la enseñanza del patrimonio en Icoaraci (distrito de Belém) con una clase de escuela primaria local, proponiendo una secuencia didáctica que analiza el patrimonio cultural histórico de Icoaraci, a través de talleres, que tratan con antiguas fuentes iconográficas, entrevistas con ancianos y visitas a lugares de memoria. Durante esta investigación, los estudiantes y las personas entrevistadas señalaron varias prácticas y costumbres relacionadas con los alimentos como rasgos de identidad, lo que nos llevó a abordar este problema.

Palabras clave: Enseñanza del patrimonio, Alimentación, Icoaraci, Historia de la alimentación, enseñanza de la Historia. 


\section{INTRODUÇÃO}

O atual distrito de Icoaraci, pertencente à região metropolitana de Belém, e dista dezoito quilômetros da capital paraense. Icoaraci reserva muitas características próprias. Até hoje, quem frequenta a localidade pode sentir um "clima bucólico" bem peculiar que ainda segue tocando seus moradores mais antigos e seus visitantes. Os cenários deste distrito de Belém, podem ser narrados pelas suas ruas, os antigos casarões que remontam as elites do período da borracha, suas igrejas, a orla banhada pelas águas da baía do Guajará com seus restaurantes de variados cardápios que vão de caldeiradas de peixes da região, caranguejos toc toc à chapas de filé bovino. Além da venda das peças de artesanato que ainda atraem turistas ao bairro do Paracuri e à feira de artesanato na orla.

Durante os debates na fase inicial das aulas oficinas, propomos discussões entre os alunos mediante questões colocadas, como; "quais práticas do cotidiano poderiam servir de referenciais identitários em Icoaraci?", entre tantas reflexões e apontamentos de alunos e alunas, registramos diversas referências à alimentação e aos costumes culinários de Icoaraci. Partindo de um dos objetivos principais dessa pesquisa e do próprio projeto de intervenção em ensino de História, que trata da aproximação desses alunos e alunas com o desenvolvimento de uma consciência histórica, possibilitando muni-los de ferramentas intelectuais e de experiências que os levem a enxergar o lugar em que habitam de maneira diferente, historicizando práticas e espaços antes tidos como comuns, e sem importância, mas que a partir da pesquisa ganham ares mais significativos no que tange a percepção das identidades que são construídas no distrito. Este exercício ao qual os alunos foram convidados a realizar com os patrimônios de Icoaraci e os lugares de memória a partir do trato com iconografias, como fotografias, cartões postais de finais do Século XIX e início do Século $\mathrm{XX}$, além das memórias dos mais velhos, nos fez perceber o brotar de olhares questionadores, que problematizavam e lograram fitar o que antes permanecia invisível aos seus olhos.

Assim se deu durante uma das aulas oficinas. Ao se referirem, por exemplo, ao vai e vem dos vendedores e carregadores do trapiche de Icoaraci, negociando suas frutas, hortaliças, legumes, pescados e, sobretudo, os paneiros de açaí abarrotados da fruta, esta que sem dúvida foi a mais mencionada entre os alunos (seja como consumo, ou ao seu comércio), no que se referia à traços comuns na comunidade que pudessem ser vistos como representativos do distrito. Nesse sentido, surgiu a possibilidade - e ao mesmo tempo a obrigação - de trabalhar também a questão da alimentação dentro do ensino patrimonial de Icoaraci. Sobretudo, mediante as novas perspectivas e possibilidades dessa temática, seja no campo da pesquisa historiográfica, seja na área de ensino de História. Por meio do tema da alimentação relacionado a história de Icoaraci, foi possível tratar das questões relacionadas à nossa pesquisa com os alunos. Surgiu como uma 


\section{Ensino de História e a temática da alimentaçõa: \\ Possibilidade acerca da identidade, memória e pertencimento. Icoaraci/PA}

Williomar de Souza PEIXOTO

forma bastante salutar de abordar percepções sobre costumes locais relacionados ao hábito de alimentar-se. Quando os alunos e alunas apontaram, por exemplo para o açaí, como uma referência em comum, nos surgiu a necessidade de tratar desse tema com os mesmos.

Fabio Pestana Ramos (2018), nos apresenta a relação didática do tema da alimentação com a História da seguinte forma;

A história também pode ser entendida através da evolução dos hábitos e costumes alimentares. Além de ser parte importantíssima da sobrevivência material da espécie, a alimentação está ligada a questões culturais e religiosas, a distinções sociais, étnicas, regionais e até de gênero. (RAMOS, 2018, p. 95).

Nesse sentido, visamos trabalhar com os alunos a crítica sobre os costumes alimentares relacionados ao seu tempo, e a possibilidade de problematizar com eles os cotidianos alimentares que se constroem no passado, por meio dos relatos de memória colhidos durante as entrevistas com os mais velhos. Dessa forma coadunamos com a proposta principal deste trabalho, que seria partir da própria vivência dos alunos, de suas experiências pessoais no lugar em que vivem, cruzadas com as experiências de pessoas mais velhas de suas famílias e da comunidade. Ou seja, trabalhar o ensino patrimonial de Icoaraci, a partir do cotidiano do aluno no tempo e espaço, dinamizando o ensino também com o tema da alimentação, apresentando algumas relações entre passado e as realidades contemporâneas locais, apontando didaticamente, e os auxiliando na percepção dos traços culturais e construções históricas sobre um hábito aparentemente sem importância; o de se alimentar.

Questões como, Porque se come isso ou aquilo? De onde vem isso ou aquilo? Quem come isso ou aquilo? São questões que levam os alunos a compreenderem suas relações com certos alimentos, estes, citados por eles, e pela memória dos moradores mais velhos.

\section{ALIMENTAÇÃO E IDENTIDADES LOCAIS}

Um dos objetivos da pesquisa realizada foi que os alunos pudessem, num primeiro momento, discutir história local, identidade e memória, por meio do trato com a memória dos moradores e parentes mais velhos, através da coleta de entrevistas. Em outro momento, se deu a ocupação dos espaços de Icoaraci para a produção de imagens, registros fotográficos dos espaços e costumes locais, que serviram como uma produção textual não escrita.

Neste sentido, baseamos as práticas didáticas em recomendações dos Parâmetros curriculares Nacionais, que nos auxiliam a compreender e a chancelar teoricamente esses objetivos com a histórica local e a educação patrimonial, haja vista o papel do ensino de História em contribuir para desenvolver a formação intelectual, fortalecer os laços de identidade com o presente e com gerações passadas, bem como, orientar as 


\section{Ensino de História e a temática da alimentaçõa: \\ Possibilidade acerca da identidade, memória e pertencimento. Icoaraci/PA}

\section{Williomar de Souza PEIXOTO}

atitudes do aluno como cidadão do mundo contemporâneo, que possa gozar desta cidadania. Participando social, política e criticamente da realidade em que está inserido.

Diante das entrevistas colhidas pelos discentes, pudemos perceber a potencialidade do trato com a memória, no sentido de resgatar vestígios de práticas, costumes e realidades do passado de Icoaraci a partir das histórias de vida de pessoas comuns, que mesmo sem saber, ajudaram a construir essa mesma história. O que Sarlo (2007, p. 17) nos aponta como sendo uma guinada necessária da pesquisa histórica para podermos enxergar nas dobras das análises hegemônicas, a valorização das minúcias, apreender as exceções à regra, revelar na vida cotidiana do passado, possíveis esquecimentos e permanecias no presente.

No entanto, seria a escola e as aulas de História, possíveis de aproximar os alunos dessa história, dos valores culturais e bens patrimoniais de Icoaraci? haja vista, que percebemos não bastar falar de uma identidade icoaraciense estabelecida entre os que lá vivem, pois segundo o que nos alerta Stuart Hall (1996), a identidade não é algo estanque, pelo contrário, está em constante mutação, por ser inevitavelmente ligada à cultura, não se trata simplesmente de um modelo identitário, plasmado e passado de geração para geração, mas sobretudo, algo que depende da construção da narrativa cultural e da história. Sendo assim, o indivíduo relaciona-se com a identidade que lhe cabe segundo seu grau de pertencimento à cultura que lhe cerca. Quando pensamos Icoaraci, devemos pensar também, além de sua cultura, seus espaços como formadores de perspectivas identitários possíveis.

No decorrer da fase das aulas oficinas realizamos rodas de debates com os alunos e alunas a partir de perguntas semelhantes às lançadas ao mais velhos. Durante um dos debates, com o tema acerca de aspectos presentes em Icoaraci e que poderiam ser definidos como próprio do local, aquilo que traria sentimentos de pertença, ou que representasse o lugar em que vivem enquanto comunidade, a aluna " $\mathrm{K}$ " logo apontou as diversas vendas de Açaí, que brotam como pontos vermelhos a cada esquina. Estes pontos vermelhos se referem às bandeiras, baldes e placas vermelhas nas esquinas das ruas. Segundo ela; "Professor, sem dúvida as vendas de açaí são bem a cara de Icoaraci, em todo canto tem uma casa de açaí, só na minha rua deve ter umas três". Em seguida, questionados sobre quais deles costumavam consumir, e com que frequência, dos 20 alunos presentes no encontro, 18 afirmaram que consomem açaí quase que diariamente no almoço.

Outro lugar apontado tanto pelos alunos quanto pelos entrevistados, que possui ligação com o tema da alimentação, foi o trapiche da orla. Segundo os participantes, a cena dos trabalhadores do porto, simbolizados no vai e vem do desembarque e transporte dos mais diversos produtos, como pescados, frutas, hortaliças, farinhas, temperos, etc. ajuda a compor a paisagem da orla de Icoaraci com as mesas dos restaurantes que acabam sendo o destino de boa parte dessa produção. Tais estabelecimentos acabaram por ocupar alguns dos prédios mais antigos do distrito, sendo alguns deles bastante imponentes, caso de um 
antigo chalé de dois andares com belos trabalhos em gradis de madeira, onde hoje funciona uma das tradicionais peixarias do local.

Um dos alunos ao concordar com a opinião de outro colega, completa ressaltando o cheiro peculiar que o trapiche possui, como vemos em sua fala; "É verdade, todo dia eu passo por lá pra vir para a escola, e dá pra sentir o cheiro de fruta misturado com peixes e tudo mais". O aluno "P", completa, nos revelando que seu tio e sua mãe trabalham com venda de farinha na terceira rua Padre Júlio Maria (conhecida como terceira rua pelos moradores), o pequeno negócio, intitulado de "Casa da Farinha", complementa a renda da família a muito tempo. Ele nos explicou que a mãe é responsável pela escolha e a compra das sacas de farinhas, e o tio assume o trabalho de transportar o produto do porto de Icoaraci para a venda da família.

A partir da fala de "P" aproveitamos para iniciar a problematização sobre a questão do abastecimento desse tipo de alimentos exatamente a partir da fala sobre a realidade colocada pelo aluno. Ao serem questionados sobre as origens dessa farinha comercializada e tão consumida em Icoaraci, assim como o já citado Açaí, obtivemos de forma unanime respostas negativas dos alunos e alunas. Dessa forma pudemos já tratar da relação de trabalho e a produção ligada à esses alimentos. Qual a condição da cadeia de trabalhadores que estão envolvidos até o momento em que esse produto chega nas mesas dos alunos? no caso do aluno "P" pudemos exemplificar o papel da sua Mãe e de seu tio, que configuram-se como trabalhadores responsáveis por comprar a farinha e comercializar diretamente com a última parte dessa relação de comercio do produto, que seria o consumidor, mas e os demais envolvidos? Quem seriam os donos das terras onde a mandioca seria cultivada para a fabricação, além da farinha, do tucupi, da goma de tapioca, sendo estes seus derivados? Além disso, convidamos os alunos a pensarem sobre a prática do consumo de tais alimentos citados por eles, como corriqueiros em Icoaraci. De onde vem? Seus avós já os consumiam? E antes de seus avós, os antepassados de Icoaraci, se deliciavam com tais iguarias, hoje tão corriqueiras?

Dessa forma pudemos problematizar a rede de inter-relações econômicas, sociais, culturais e históricas que o alimento possui. Exposto isto, percebemos que a alimentação é uma categoria histórica com aspectos que devem ser pensados enquanto suas relações de trabalho, relações sociais, formas de agricultura, posses da terra, além dos perfis patrimoniais que possuem, relacionados à identidades e a diversidade cultural.

Dentro dessa compreensão, encorajamos os participantes para que no passo seguinte, que tratou-se da entrevista dos mais velhos, pudessem assim, entrevistar também os vendedores de Icoaraci que fornecem o alimento para suas famílias, sobre o processo de compra e origem do produto. Um passo seguinte seria a visita aos lugares apontados pelos alunos e pelas gerações anteriores para o registro em fotografia dos alunos. Nos pareceu também necessário realizar o contato para uma conversa com os trabalhadores do porto de 


\section{Ensino de História e a temática da alimentaçõa: \\ Possibilidade acerca da identidade, memória e pertencimento. Icoaraci/PA}

Williomar de Souza PEIXOTO

Icoaraci, sobretudo aqueles que fazem por meio de barcos os transportes desses produtos, caso do açaí, das frutas, da farinha, dos pescados, como o camarão, as hortaliças em geral, e muito foi informado aos alunos sobre a origem dos produtos que por ali chegam. Boa parte vem de famílias moradoras das ilhas próximas, como é o caso da Ilha das onças, Cotijuba, etc. Tais famílias cultivam hortaliças, frutas, bem como realizam a extração do açaí, entre outros produtos.

Figura 1: Carro de venda de frutas no trapiche de Icoaraci.

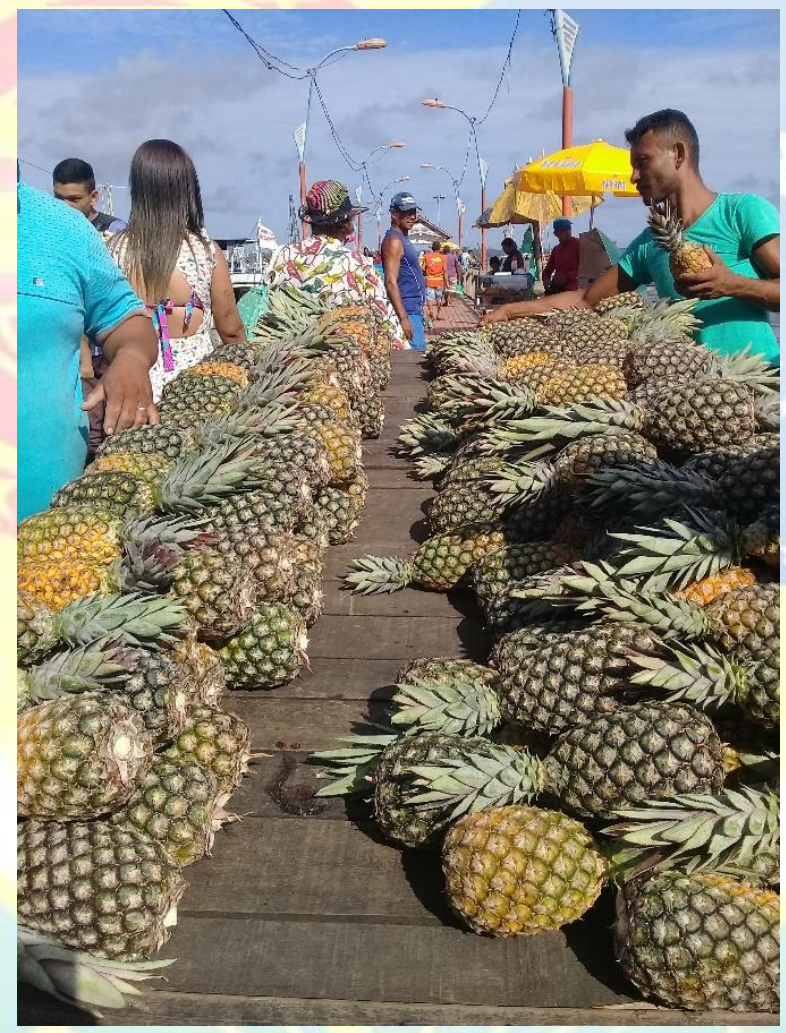

Fonte: Alunos do projeto

Nesta fase do debate sobre a alimentação buscamos tratar da relação de produção e da cadeia de trabalhadores que atuam para que tais produtos alcancem os moradores de Icoaraci, com o objetivo de problematizarmos temas e termos comuns à História em vários outros contextos, como é o caso de latifúndio e minifúndio, agricultura familiar, cidade e campo, cultura artesanal e cultura fabril, entre outras. Os alunos acabaram por demonstrar maior facilidade no trato e compreensão de tais temas conforme se debatia, sobretudo, devido ao fato de partirmos da própria realidade desses indivíduos, trabalhando aquilo que eles consomem diariamente. 


\section{Ensino de História e a temática da alimentaçõa: \\ Possibilidade acerca da identidade, memória e pertencimento. Icoaraci/PA}

Williomar de Souza PEIXOTO

Propomos, assim, trabalhar mediante uma metodologia que leve o aluno para fora da sala de aula e que promova a análise de Icoaraci, como lugar de relevância no processo de construção e desenvolvimento das identidades. Almeju-se que os participantes pudessem dialogar e refletir sobre sua condição como indivíduos integrantes desse lugar, e sua ligação nessa temporalidade, ampliando a noção de historicidade do aluno, e a possibilidade de se enxergar como ator capaz de transformar a realidade e a própria história de seu lugar, como nos salienta Barca (2004, p.134);

[...] uma compreensão contextualizada do passado, com base na evidência disponível, e pelo desenvolvimento de uma orientação temporal que se traduza na interiorização de relações entre o passado compreendido, o presente problematizado e o futuro perspectivado.

Fazendo assim, por meio da criticidade histórica, uma relação entre sua bagagem de experiências pessoais, seu presente, e a possibilidade de redesenhar seus horizontes de expectativas.

\section{Figura 2 e 3: Trabalhador desembarcando frutas no trapiche de Icoaraci (esquerda) e camarões secando ao sol (direita)}
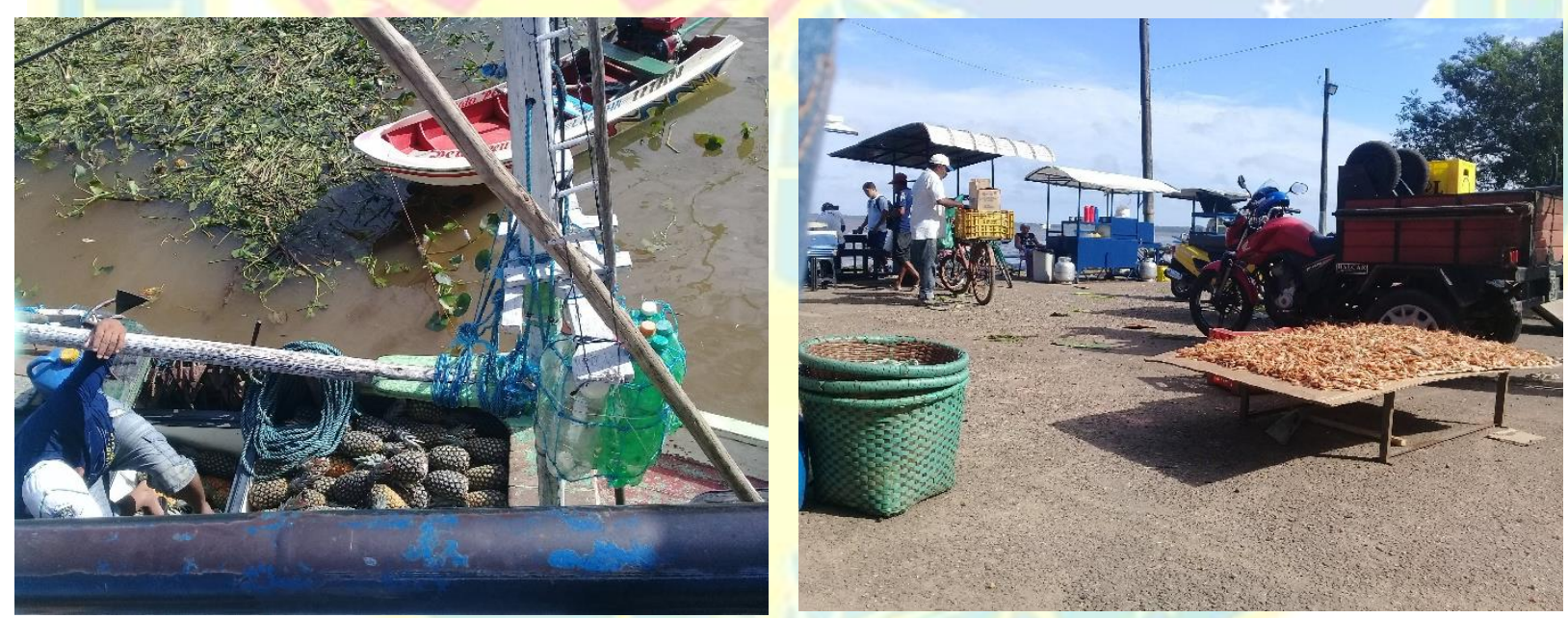

Fonte: Alunos do Projeto

Outro aspecto trabalhado com os alunos foi o caráter da importância do lugar em si como lugar de memória, já que, em várias entrevistas colhidas obtivemos citações sobre o trapiche como lugar que guarda memorias do lugar, bem como a antiga ponte de desembarque dos vapores que encostavam na vila.

Assim se deu, também, quando abordamos o aspecto histórico e social dos alimentos, sendo estes preenchidos por construções temporais e contextuais de cada povo, e que ganha novas características conforme as transformações sociais, econômicas e culturais se modificam. 
É o caso do Açaí, que tem suas origens como alimento ligado aos povos indígenas da região norte, como demonstra Macêdo (2016, p.196), ao tratar das primeiras citações dos missionários franceses na região. A historiadora aponta povos como os Aruans, Anajazes, Mocohons, Mapuazes e Tupinambás como fabricantes e apreciadores da bebida oriunda dos Coquinhos escuros extraídos das palmeiras tão comuns na paisagem da região. Sobre esta origem ligada aos povos tradicionais da região, decidimos trabalhar essa contextualização com os alunos a partir da mitologia oriunda destes povos e que guarda relação direta com o ambiente em que vivem; a floresta, lugar que segundo Macêdo (2016, P. 196) liga-se ao imaginário desse povos, sobretudo, na forma de criação de seus mitos.

O mito de Iaça, nos permitiu além de abordar o açaí como um alimento com tradições indígenas, tratar das diferentes formas de linguagens de culturas diferentes, exemplo da cultura oral. Focando na construção de compreensões e respeitos à culturas diversas, como é o caso das etnias indígenas e suas formas de compreensão e identificação das realidades, suas representações sobre aquilo que os cercam e que criam suas identidades (Souza, 2016).

Tais formulações mitológicas acerca de alimentos, se mostram comuns em diversas outras culturas ao redor do mundo, e em diferentes estágios do desenvolvimento humano, nas mais variadas civilizações, como nos apresenta Franco:

No folclore da mesopotâmia, o mel era uma substância magica, com propriedades medicinais e purificadoras do organismo [...] nas culturas mediterrâneas, o sal era tão importante para a conservação dos alimentos que se tornou, no advento do cristianismo, símbolo da renovação do mundo "vós sois o sal da terra. Se o sal perder a força, com que se salgará?" [...] Há milhares de anos, a oliveira ocupa lugar de destaque na vida das populações da orla do Mediterrâneo. Associada a mitos e práticas religiosas. (FRANCO, 2001, p. 31)

Dentro da sala de aula, não é difícil percebermos muitas vezes certo nível de conhecimento dos alunos acerca da alimentação de alguns povos distantes geograficamente e culturalmente. Podemos exemplificar Culturas antigas como a egípcia que é lembrada, por exemplo, pela larga produção de cerveja, ou os gregos na produção de azeite de oliva. Diante disso, ao tratarmos da questão da alimentação dentro de uma perspectiva patrimonial, e após a citação do açaí pelos alunos, nos pareceu importante discutir tal construção patrimonial ligada às origens históricas do fruto e a representação mitológica do mesmo, sobretudo, comparando tais tradições alimentares dos povos tradicionais da região amazônica com diferentes culturas, que costumam ser mais bem privilegiadas nos currículos de História, sobretudo pelo caráter enrijecido e padronizado sobre os fantasmas do eurocentrismo e de uma história tripartite que os currículos ainda costumam carregar. Estes, em geral ainda Tratam dos temas dispostos em uma lógica histórica linear, 


\section{Ensino de História e a temática da alimentaçõa: \\ Possibilidade acerca da identidade, memória e pertencimento. Icoaraci/PA}

Williomar de Souza PEIXOTO

que organiza os processos de transformação da humanidade partindo de uma antiguidade europeia, que caminha entre altos e baixos rumo ao progresso de uma civilização vista como vencedora.

Este tipo de percepção histórica anula entre os alunos a capacidade de entender o mundo pelo viés da pluralidade cultural, compreendendo diferenças e as respeitando, ao invés de vê-las como inferiores, ou atrasadas e menos importantes. Nesse sentido, propomos realizar um esforço de comparação entre culturas do mediterrâneo, por exemplo, com os tupinambás, e o caminho para essa possibilidade foi exatamente o açaí e seu mito de criação.

Dentro desse viés de ação, propormos tratar do açaí pela perspectiva da importância cultural que o fruto guarda para a Amazônia, segundo Socorro Simões, coordenadora do programa "O imaginário nas narrativas orais populares da Amazônia paraense”. (IFNOPAP-UFPA), além de estar na mesa do povo, o açaí está presente no imaginário paraense até os dias de hoje, sobretudo em múltiplas narrativas sobre sua origem, é o caso da lenda de Iaça, narrativa muito comum nas memórias de pessoas, sobretudo, das mais velhas e de localidades no interior do estado. Além disso a pesquisadora após reunir mais de 5 mil narrativas em 118 municípios do Pará, sobre as origens do alimento, define que de modo geral, a lenda de Iaça tem ligação com a sobrevivência destes povos, trata de sacrifícios para a perduração de uma comunidade. Simões (2018) nos coloca também a relação dessas comunidades entrevistadas como de dependência orgânica em vários momentos;

\footnotetext{
"Há uma referência nesta conclusão da lenda à 'sobrevivência graças ao açaí' e ao 'sacrifício para obtê-lo', que existe até hoje, especialmente entre famílias com menos recursos que se alimentam, trabalham e vivem graças a este fruto".
}

Percebemos, assim, que para além do papel cultural importante que o alimento carrega, temos também sua função social, como mencionado acima. Importante abordar este aspecto do alimento com os alunos, sobretudo quando pensamos sobre tipos de alimentos bases para diferentes sociedades, e os papéis que estes assumem no processo de desenvolvimento destas civilizações, assim como do contato com outras culturas diferentes, o que acaba por transformar práticas culinárias, assim como formar diferentes representações alimentares dentro de cada sociedade. Neste sentido, para além das origens indígenas do açaí, perpassamos também o caráter social do alimento com os alunos e alunas, e as transformações que estes sofrem no decorrer do tempo. Pois, por meio da análise das práticas alimentares de uma sociedade podemos fazer leituras mais complexas sobre, por exemplo; fome, miséria, pobreza e classes sociais.

Tal abordagem se apresenta como uma ferramenta deveras eficaz na busca pela formação de um pensamento crítico e a compreensão entre os estudantes destas realidades sociais que os cercam. Tal como reforça Ramos; 
O debate envolvendo a fome e a miséria também demanda o estudo do passado para formar indivíduos críticos imunes à manipulação ideológica deste tema amplamente utilizado por políticos e outros grupos [...] estudando a alimentação em sala de aula, obviamente aplicada ao seu objeto especifico de ação pedagógica, o professor de História pode estimular questionamentos embasados em dados concretos, e dessa forma colaborar para a formação de indivíduos mais conscientes. (RAMOS, 2018, p. 98-99).

Por meio da análise histórico-social de apenas um alimento citado pelos alunos e parte dos idosos entrevistados, no caso o açaí, podemos apresentar possibilidades de debates sobre por exemplo, aspectos sociais que cada alimento carrega. Esta perspectiva possibilita o desenvolvimento de um pensamento crítico no aluno, onde estes são levados a construir a partir da análise daquilo que é cotidiano. Isto se ancora no que fora pensado por Paulo Knaus (2014, p. 27) e Mario Carretero (2010, p. 21), em uma perspectiva de prática dialética do ensino, ao passo que visa substituir a transposição didática, por um processo de construção do conhecimento histórico, mediante uma didática dialógica entre alunos e professor, rompendo com a normatização do saber. Tal método guarda a possibilidade de desenvolver no aluno um aprendizado significativo.

Ainda sobre a questão do açaí, Sidiana Macêdo (2016) em sua tese sobre a cozinha mestiça em Belém do século XIX, nos descreve sobre as práticas de alimentação envolvendo o açaí, bem como os sujeitos históricos que faziam uso de várias maneiras diferentes. A historiadora nos mostra a relevância que o açaí possuía na dieta da cidade durante os séculos XVIII e XIX, sendo consumido misturado com água, açúcar, ou apenas com farinha de mandioca. Outras vezes em forma de mingau, e essa forma, por exemplo, segundo a autora nos ajuda a diferenciar por exemplo, as formas mais tradicionais de consumo, ligado às práticas indígenas, e modos de preparos que sofrem influência no decorrer do tempo. A partir do processo de preparo como mingau misturado ao arroz, por exemplo, teríamos o que Macêdo identifica como um processo de mestiçagem do alimento. O hábito de consumi-lo com outros ingredientes, como a farinha de mandioca, os peixes (como o pirarucu), camarões, ou outros salgados remetem ao modo indígena de consumo, no entanto o ato de adicionar açúcar, já caracteriza-se como um alimento mestiço, pois estaria relacionado ao contexto histórico pós colonização, e do estabelecimento da indústria açucareira no Brasil. (MACÊDO, 2016, p. 202)

Dentro deste mote, apesar do consumo do açaí ser, a priori, comum à toda a sociedade belenense, a adição de açúcar, por exemplo, pode servir como característica que distingue classes sociais durante os séculos XVIII e XIX, uma forma de adentrarmos às peculiaridades sociais por meio dos costumes alimentares. Segundo a autora;

No geral, o açaí era consumido sem açúcar e como parte importante das refeições. Penso que a adição de açúcar surge como parte de uma maneira de 
diferenciação de consumo entre as gentes de menor posição social e aquelas que tinham poder econômico elevado. Neste aspecto de consumo, vê-se claramente, que a forma de tomar açaí está inserida num ritual de poder simbólico. O açúcar sempre foi visto como um alimento que estava atrelado a status social. Ao mesmo tempo, observamos no uso do açúcar um processo de mestiçagem no consumo desse alimento já no século XVIII (MACÊDO, 2016, p. 199).

Importante salientar, que a possibilidade de tratar das classes populares na história local, ou regional com os alunos, torna-se motivador, pois a prática de consumir o alimento foi citada pelos alunos exatamente partindo de referenciais concretos, ao serem questionados sobre aquilo que pode servir como características identitárias do lugar onde vivem.

Macêdo (2016) nos ajuda ainda a compreender que desde, pelo menos, o século XVIII o açaí, mais do que uma iguaria ligada à práticas alimentares refinadas para grupos sociais mais abastados, era antes, base da alimentação para as camadas mais pobres da cidade, geralmente, consumida com farinha de mandioca e carnes salgadas, justamente para aumentar seu poder nutritivo, o que nos leva a inferir que o hábito constante nesse período pelas pessoas mais pobres estava ligado à necessidade de alimentar-se, e a facilidade de encontrar o fruto no local. Como nos fica claro na seguinte citação.

Para o seu preparo, emprega-se a polpa de açaí triturada e diluída com água. Na mistura entra também uma boa quantidade do pericarpo, ou casca, da fruta, o que se reconhece pelos fragmentos ásperos e insípidos que se prendem no céu da boca. Os paraenses não pertencentes à elite a bebem misturada com farinha de mandioca, o que aumenta seu poder nutritivo. Este será sem dúvida o motivo por que a população pobre a consome tão constantemente (WALLE, 2006, p. 312, apud MACÊDO, 2016, p. 199)

Ainda dentro dessa temática, outro aspecto do consumo do açaí durante o século XIX, que pôde ser tratado com os alunos está relacionado a alimentação dos indivíduos escravizados. Em artigo elaborado sobre as práticas alimentares dos escravos na Amazônia, Bezzera Neto e Macêdo (2009), nos apresentam os usos do açaí como algo comum entre os indivíduos cativos na sociedade paraense. Além do aspecto alimentar, o açaí ganhava caráter de meio de sobrevivência econômica para os negros, fossem eles de ganho, ou fugidos, serviam como meio de sobrevivência ao trabalharem com a coleta destes nos interiores e a consecutiva venda nas feiras, portos e praças de Belém. Assim como o açaí, a farinha também era consumida em demasia, base da alimentação escrava, tão apreciada ao ponto de ocorrerem casos em que escravos fugidos que haviam logrado permanecerem soltos durante anos, ao buscarem comprar ou trocar farinha nas vilas, acabavam sendo capturados (BEZERRA NETO; MACÊDO, 2009, p. 8).

Este tema sobre alimentação dos escravos quando tratado com os alunos, chamou particularmente muito a atenção dos mesmos. A maioria mostrou-se impressionada ao saber que escravos também consumiam açaí. Aquele alimento tão comum à maioria deles já havia sido consumido além de seus avós, 
também por escravos e os primeiros indígenas que ali habitavam. Este estranhamento daquilo tão corriqueiro em seu dia-a-dia, é exatamente o gatilho para que se inicie um processo de tomada de consciência acerca da historicidade que cerca sua realidade, onde até mesmo seus hábitos alimentares podem ser delimitados historicamente, sendo fruto de um contexto, como nos aponta Franco (2001, p. 26); "Os homens comem como a sociedade os ensinou. Os hábitos alimentares decorrem da interiorização, desde a mais tenra infância, de regras e de restrições". Além de ajudar na concepção entre os alunos de que aquele passado de escravidão, não está tão distante assim, e que existe muito de passado no presente em que eles vivem. A abordagem do alimento no decorrer do tempo, pode ser uma boa ferramenta para fazer o aluno compreender a formação cultural do Brasil como múltipla e riquíssima pela contribuição de diversas culturas distintas. Mas que contudo, muitas vezes só conseguimos perceber uma, a qual faz referência à branca europeia.

A partir dessas temáticas, torna-se possível tratar com os alunos a noção de que os alimentos podem nos ajudar a situar quem somos socialmente, apontam diferenças econômicas entre grupos sociais, assim como nos dias atuais. Mas, que ao mesmo tempo, certos alimentos, dependendo no contexto em que estão inseridos, também podem romper certas barreiras, no caso do açaí, este consegue visitar tanto as mesas de famílias com melhores condições econômicas, que compram o litro por valores altíssimos para saborear com peixes mais caros, ou em restaurantes hoje especializados em atender uma parcela exclusiva da sociedade, aquela que consegue pagar o preço. E ao mesmo tempo, está presente na mesa de famílias mais pobres de Icoaraci, que em muitos casos, enxergam este alimento como a única fonte de alimento, e que ao invés dos peixes caros, ou camarões, complementam o vinho arroxeado simplesmente com farinha d'agua, ou algum salgado embutido de carne, como mortadela, ou salsichas, como bem mencionaram alguns dos alunos, durante os debates.

Para além do que possa parecer, tais aspectos aqui tratados não são isolados uns dos outros, antes disso, todas as características e possibilidades aqui tratadas, usando o exemplo do açaí, que fora citado pelos alunos, estão situadas na perspectiva do alimento como referência de identidades de comunidades, sendo estas, resultado de construções histórico culturais, e suscetíveis à representações diversas. A alimentação é cultura, e vai de um simples ato de comer, até poder transformar-se em algo cheio de sentidos e referências concernentes à hábitos e práticas de um coletivo. O que nos ajuda a compreender certos alimentos que ganham relevância como representações e tipos patrimoniais à essa comunidade. $\mathrm{O}$ ato do ensino de História se propor a tratar do tema sobre o alimento como identidade patrimonial, insere-se na discussão sobre a busca por consciência histórica em alunos e a questão dos conteúdos. Antes de mais nada, ao tratar de alimentação com os alunos, nos é possível partir da realidade tangível dos alunos, exatamente o que Rusen 
(1992) nos coloca como ponto importante no trabalho com alunos acerca de uma consciência histórica, vejamos;

\begin{abstract}
A história, que afinal deveria fornecer reflexões e respostas elaboradas - ainda que provisórias - sobre a historicidade desses temas cruciais para a vida do aluno, incluindo-os em grandes temas cruciais para a vida do aluno, incluindo-os em grandes quadros que permitem entender seus fundamentos, vinculações e consequências, acaba por oferecer somente respostas mais ou menos sofisticadas sobre Napoleão Bonaparte ou sobre os combates das guerras do século XX. Embora esses sejam temas importantes, não devem suplantar a necessidade de compreender o mundo imediato do aluno (RUSEN, 1998, apud CERRI, 2011, p. 124)
\end{abstract}

Dessa forma, compreendemos como possível para um estudo patrimonial lançar mão de temáticas como a alimentação, sobretudo quando pensamos acerca da questão das identidades como parte importante no ensino de História.

Montanari (2009, p. 241) em seu trabalho sobre o mito da Bolonha gorda, o autor analisa exatamente esta construção das identidades que se constroem por meio de trocas e experiências culturais no decorrer do tempo na cidade italiana. Nesse sentido, comparadamente, temos o alimento trabalhado com os alunos de Icoaraci perspectivado em sua construção histórica e cultural, como parte da cozinha mestiça da região amazônica. Tal viagem sobre esta construção do açaí no tempo como pano de fundo, nos possibilita enxergar e trabalhar com os alunos e alunas a história local, noções sobre os patrimônios locais e o surgimento de referenciais identitários dentro do ensino de História.

\title{
CONSIDERAÇÕES FINAIS
}

Os encontros durante o projeto de intervenção didática aqui tratado, mostraram-se eficazes no que diz respeito ao contato dos discentes com as riquezas culturais locais de Icoaraci. Apresentando-se como ferramenta poderosa no objetivo de ampliar a crítica dos alunos para o tema do patrimônio cultural e histórico. Percebemos o advento de olhares e elucubrações que passaram a problematizar o próprio local em que vivem, e surgindo olhares treinados para enxergar aspectos que antes eram invisíveis aos alunos.

Tratar do açaí como possiblidade do trato da alimentação para debater a história local de Icoaraci, bem como, ajudando no processo de entendimento de como se constroem socialmente patrimônios históricos e culturais, lugares de memória e a importância de tê-los em sua formação, resultou em positivo resultado no termino das aulas oficinas e da produção das imagens. Perceber nos olhares dos alunos, e na autonomia de suas representações por meio das fotografias, a compreensão de que em cada canto, rua, praça, estabelecimento e práticas de Icoaraci, existe história e importância para sua formação como cidadão, nos demonstrou o potencial da sequência didática envolvendo o ensino patrimonial e o tema da alimentação, bem como as diferentes possibilidades e perspectivas. 


\section{Ensino de História e a temática da alimentaçõa: \\ Possibilidade acerca da identidade, memória e pertencimento. Icoaraci/PA}

Williomar de Souza PEIXOTO

\section{REFERÊNCIAS}

Açaí - Lendas e Mitos em Só História. Virtuous Tecnologia da Informação, 2009-2019. Consultado em 18/08/2019 às 01:07. Disponível na Internet em http://www.sohistoria.com.br/lendasemitos/acai/

BARCA, I. Aula oficina, do projeto à avaliação. In: Para uma educação histórica de qualidade, 2004, Braga. Actas das IV Jornadas Internacionais de Educação Histórica. Braga: Uminho, 2004. pp. 131-144.

BEZERRA NETO, Jose Maia; MACÊDO, Sidiana da Consolação Ferreira de. A quitanda de joana e outras histórias: Os escravos e as práticas alimentares na Amazônia (séc. XIX). Histórica - Revista Eletrônica do Arquivo Público do Estado de São Paulo, nº 38, 2009.

CERRI, Luís Fernando. Ensino de História e consciência histórica: implicações didáticas de uma discussão contemporânea. Rio de Janeiro: Editora FGV, 2011.

FLANDRIN, Jean-Louis \& MONTANARI, Massimo. História da Alimentação. São Paulo: Estação Liberdade, 1998.

FRANCO, Ariovaldo. De caçador a gourmet: uma história da gastronomia. $5^{\text {a }}$ ed. - São Paulo: Editora Senac São Paulo, 2001.

HALL, Stuart. Identidade cultural e diáspora. Revista do Patrimônio Histórico e Artístico Nacional. Rio de Janeiro: IPHAN, 1996, pp. 68-75.

MACÊDO, Sidiana da Consolação Ferreira de. A cozinha mestiça: história da alimentação em Belém. 2016. Tese (doutorado em História social da Amazônia). Belém: Instituto de Filosofia e Ciências Humanas, Universidade Federal do Pará, 2016.

MONTANARI, Massimo. A cozinha, lugar da identidade e das trocas. In: O Mundo na cozinha: história, identidade, trocas. São Paulo: Estação Liberdade: Senac, 2009.

MONTEIRO, Glauce. Lenda do açaí mostra importância social do fruto. UFPA - Ascom, Assessoria de comunicação institucional, 2015. Disponível em: https://ascom.ufpa.br/index.php/banco-de-pautas/75acai/144-lenda-do-acai-mostra-importancia-social-do-fruto. Acesso em: 10 de agosto de 2019.

RAMOS, Fábio Pestana. Alimentação, In; PINSKI, Carla Bassanesi (Org.) Novos temas nas aulas de História. $2^{a}$ ed. São Paulo: Contexto, 2018.

SARLO, Beatriz. Tempo Passado. Cultura da Memória e Guinada Subjetiva. São Paulo: Companhia das Letras; Belo Horizonte: Editora UFMG, 2007.

SOUZA, Fábio Feltrin. Nova História Cultural: Uso das linguagens e percursos possíveis. In: ENSINO de História: Memória e Identidade. Jundiaí: Paco Editorial, 2016.

WALLE, Paul. No Brasil, do Rio São Francisco ao Amazonas. Brasília: Senado Federal, 2006.

Texto recebido em: 30/03/2020

Texto aprovado em: 22/04/2020

Revista do Instituto Histórico e Geográfico do Pará (IHGP), (ISSN: 2359-0831 - on line), Belém, v. 07, Dossiê "História da alimentação e do abastecimento na Amazônia", p. 109 - 123, Maio / 2020. 